\title{
Mg-based Nanocomposites for Hydrogen Storage Containing Ti-Cr-V Alloys as Additives
}

\author{
Ricardo Floriano ${ }^{a}$, Daniel Rodrigo Leiva ${ }^{b}$, João Guilherme Dessï, Alexandre Augusto Cesário \\ Asselli, Alberto Moreira Jorge Junior ${ }^{b}$, Walter José Botta ${ }^{b}$ \\ ${ }^{a}$ Faculdade de Ciências Aplicadas, Universidade Estadual de Campinas, Rua Pedro Zaccaria, CEP \\ 13484350, Limeira, SP, Brazil \\ ${ }^{b}$ Departamento de Engenharia de Materiais, Universidade Federal de São Carlos, Rod. Washington \\ Luiz, $\mathrm{km}$ 235, 13565-905, São Carlos, SP, Brazil \\ 'Institut de Recherche sur l'Hydrogène, Université du Québec à Trois-Rivières, Trois-Rivières, Québec, \\ Canada
}

Received: February 29, 2016; Revised: July 20, 2016; Accepted: August 16, 2016

\begin{abstract}
In this study, we have investigated the synthesis, microstructure and hydrogen storage properties of Mg-based nanocomposites containing different concentrations of $\mathrm{TiCrV}$ and $\mathrm{TiCr}_{1.2} \mathrm{~V}_{0.8}$ alloys. The Mg-based nanocomposites of Mg containing Ti-Cr-V additives were prepared by reactive milling (RM) under hydrogen atmosphere. The structural characterization revealed the presence of the $\beta-\mathrm{MgH}_{2}$, $\gamma-\mathrm{MgH}_{2}$ and $\mathrm{BCC}$ phases in the powders samples after RM. In addition, a very refined and homogenous microstructure with average $\mathrm{MgH}_{2}$ crystallite size of around 10-12 nm was observed, including a nanometric dispersion of the additives in the magnesium hydride matrix. The doping with $\mathrm{TiCrV}$ and $\mathrm{TiCr}_{1,2} \mathrm{~V}_{0,8}$ greatly improves the hydrogen desorption behavior of $\mathrm{Mg}$ in comparison with the sample without additive, resulting in the lowest onset temperature $\left(240^{\circ} \mathrm{C}\right)$ for the sample containing $5 \% \mathrm{~mol}$. of TiCrV. Very fast absorption and desorption kinetics at $275^{\circ} \mathrm{C}$ and $300{ }^{\circ} \mathrm{C}(7$ minutes and 5 minutes for full desorption and absorption, respectively) were observed in the samples containing $\mathrm{TiCrV}$ and $\mathrm{TiCr}_{1,2} \mathrm{~V}_{0,8}$ without any notable difference between the type of additive used in comparison with the pure sample. However, a slight reduction in hydrogen capacity is observed in the mixtures than for the pure sample (6.7 wt.\% against $7.3 \mathrm{wt} . \%)$.
\end{abstract}

Keywords: Hydrogen storage; Magnesium hydride; Reactive Milling; BCC Alloys; Additives.

\section{Introduction}

Hydrogen is considered the ideal energy carrier since it has a very high energy content and water is the only by-product after its use in a fuel cell or internal combustion engine'. However, the development of safe and effective forms of $\mathrm{H}_{2}$ storage remains as a critical technological challenge. Gaseous hydrogen can react with some metals and alloys to form metal or complex hydrides, which allow hydrogen storage at the solid state. This represents a more suitable form of storage than the use of $\mathrm{H}_{2}$ gas at high pressures or alternatively liquid hydrogen at very low temperatures ${ }^{1}$.

$\mathrm{MgH}_{2}$ is a very interesting phase for hydrogen storage, mainly due to the low cost of $\mathrm{Mg}$ and its very high gravimetric capacity (7.6 wt.\%), being the highest among the metal hydrides ${ }^{2}$. However, the conventional (microcrystalline) magnesium hydride has some disadvantages, as slow $\mathrm{H}$-absorption/desorption kinetics even at relatively high temperatures (generally, a few hours are needed even at $400^{\circ} \mathrm{C}$ ). On the other hand, $\mathrm{MgH}_{2}$ produced by high-energy ball milling (HEBM) can present very fast reaction kinetics

\footnotetext{
* e-mail: florianopower@gmail.com
}

at lower temperatures ${ }^{3-5}$ (e.g: a few minutes at $300^{\circ} \mathrm{C}$ ). HEBM is not only suitable to increase the concentration of defects and to reduce the crystallite size to nanometer scale but also to introduce a fine dispersion of additives with catalytic effect. Different families of additives were tested with success to improve the hydrogen storage properties of nanocrystalline $\mathrm{MgH}_{2}$, producing nanocomposite powders. Transition metals, their oxides or fluorides are known to exhibit important catalytic action during the reactions of hydrogen absorption/desorption by $\mathrm{Mg} / \mathrm{MgH}_{2}{ }^{6-8}$. However, clear descriptions of the mechanisms involved in the catalytic action of the additives are still unclear in most of the cases, remaining as an interesting topic of fundamental research ${ }^{9}$, even considering the high amount of studies published on this topic over the last years ${ }^{1-10}$.

On the other hand, Ti-Cr-V alloys were one of the first systems studied for hydrogen storage applications ${ }^{11,12}$. These alloys exhibit a BCC solid solution structure and maximum hydrogen absorbing capacity of these alloys can reach about $3.7 \mathrm{wt} \%$ at room temperature (with hydrogen atoms dissolved in the BCC structure). However, these alloys suffer from disadvantages like difficult activation treatment, 
poor kinetics, large hysteresis, low cyclic stability, high desorption temperature and high cost. In order to improve the hydrogen storage characteristics of Ti-Cr-V system, all these drawbacks has been overcome by the preparation of these alloys by using HEBM, heat treatment and by the addition of different catalysts in the alloys ${ }^{14-18}$. The substitution of Ti, $\mathrm{V}$ or $\mathrm{Cr}$ with elements like $\mathrm{Zr}, \mathrm{Co}, \mathrm{Fe}$ or Mn leads to drastic changes in the hydrogen storage properties of the alloys due to the formation of secondary Laves phases that coexist with the BCC phase ${ }^{12,13}$. The presence of a secondary Laves phase makes the activation procedure easier as compared to pure BCC phase, though the secondary phase decreases the maximum hydrogen storage capacity ${ }^{12,17}$. Thus, combining magnesium with a BCC Ti-Cr-V alloy could be an interesting approach to produce a composite material, presenting an enhanced hydrogen absorption/desorption behavior, when compared to the $\mathrm{MgH}_{2}$ or to the BCC alloy taken alone as hydrogen storage materials ${ }^{19}$.

In this study, we showed results of the synthesis, microstructure and hydrogen storage properties of Mg-based nanocomposites containing two types of BCC alloys as additives, $\mathrm{TiCrV}$ and $\mathrm{TiCr}_{1.2} \mathrm{~V}_{0.8}$. The nanocomposites were prepared by reactive milling under hydrogen atmosphere and different concentrations of the both additives were tested, from 2.5 to $7.5 \mathrm{~mol} \%$. The correlations between the microstructure and obtained hydrogen storage properties are discussed.

\section{Experimental}

$\mathrm{TiCrV}$ and $\operatorname{TiCr}_{1,2} \mathrm{~V}_{0,8}$ alloys used as additives were produced by arc-melting from the pure elements (Ti: Alfa Aesar, 99.7\%; Cr: Aldrich, 99.7\%; V:CERAV, 99.7\%). The mixtures were melted three times to ensure a good level of homogeneity and the as-cast alloys were crushed into small pieces with diameters of a few millimeters using a forging die. The Mg-based nanocomposites were obtained by reactive ball milling of pure magnesium (Aldrich, 98\% of purity) containing $2.5,5$ and $7.5 \mathrm{~mol} \%$ of $\mathrm{TiCrV}$ or $\mathrm{TiCr}_{1.2} \mathrm{~V}_{0.8}$. A tool steel milling vial with an internal volume of $160 \mathrm{~cm}^{3}$ containing 25 chromium steel milling balls was used. The ball-to-powder mass ratio was fixed at 40:1 and a hydrogen pressure of $3 \mathrm{MPa}$ was employed. Reactive milling was performed in a Fritsch P6 planetary mill for 24 h. Before and after processing by RM, the powder samples were handled and stored in a MBraun Labmaster 130 glovebox. X-ray diffraction (XRD) analysis was carried out in a Rigaku Geigerflex diffractometer equipped with $\mathrm{CuK}_{\alpha}$ radiation and a graphite monochromator. The XRD data was also used to calculate the mean crystallite size through Scherrer analysis. For that, the contribution of the instrumental broadening was deconvoluted using a known pattern (silicon). The hydrogen desorption behavior of the powder samples was investigated by Differential Scanning
Calorimetry (DSC) performed in a NETZSCH STA 449C coupled to quadrupole mass spectrometer (QMS). Samples with mass around $10 \mathrm{mg}$ were used. The measurements were performed with the heating rate of $10 \mathrm{~K} / \mathrm{min}$ under argon flux of $20 \mathrm{ml} / \mathrm{min}$. Scanning and transmission electron microscopy (SEM and TEM) were performed respectively in a Phillips XL30 FEG and in a FEI TECNAI G2-F20 microscope. The hydrogen absorption/desorption kinetics were evaluated in a home-made Sievert apparatus using samples with mass of around $100 \mathrm{mg}$ and at two different temperatures, $275^{\circ} \mathrm{C}$ and $300^{\circ} \mathrm{C}$, respectively. The pressure used at absorption was 20 bar and 1 bar for desorption.

\section{Results and Discussion}

Figure 1 shows the XRD patterns of the as-cast TiCrV and $\mathrm{TiCr}_{1.2} \mathrm{~V}_{0.8}$ alloys produced by arc-melting followed by crushing in a forging die. It can be noticed that both alloys display only the BCC-type phase, and the Bragg peaks of the $\mathrm{TiCr}_{1.2} \mathrm{~V}_{0.8}$ alloy present a slight shift in $2 \theta$ to the left (better viewed in the dashed line located at $2 \theta: \sim 42,61$ and $78^{\circ}$ ) in comparison with the TiCrV alloy. This shift to lower $2 \theta$ position, it's due to the higher $\mathrm{Cr} / \mathrm{V}$ ratio of the $\mathrm{TiCr}_{1.2} \mathrm{~V}_{0.8}$ composition that increases the crystal cell parameters of the BCC-structure ${ }^{20}$.

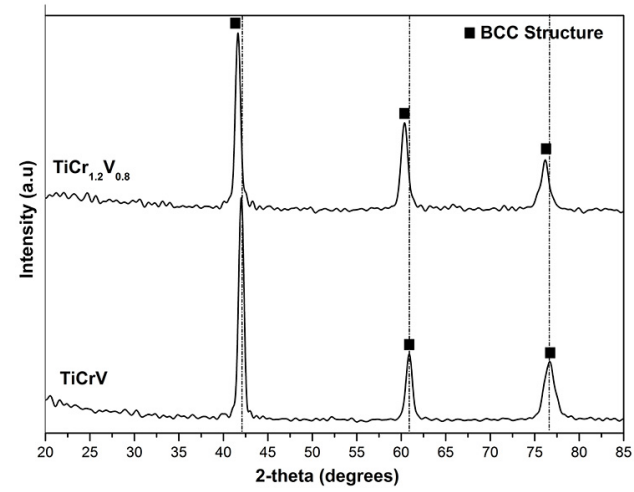

Figure 1. XRD patterns of the as-cast $\mathrm{TiCrV}$ and $\mathrm{TiCr}_{1,2} \mathrm{~V}_{0,8}$ alloys produced by arc-melting followed by crushing.

Figure 2 shows the XRD patterns of the Mg pure and the Mg-based nanocomposites containing 2.5, 5.0 and $7.5 \mathrm{~mol} \%$ of $\mathrm{TiCrV}$ and $\mathrm{TiCr}_{1.2} \mathrm{~V}_{0.8}$ as additives after $24 \mathrm{~h}$ of reactive milling. In these XRD patterns, the following phases were identified: $\beta-\mathrm{MgH}_{2} ;-\mathrm{MgH}_{2}, \mathrm{BCC}$-type phase and $\mathrm{Mg}$. These XRD patterns reveal that the most part of $\mathrm{Mg}$ was converted into the $\beta-\mathrm{MgH}_{2}$ and the high-pressure $\gamma-\mathrm{MgH}_{2}$ phases after reactive milling. Some diffraction peaks of the $\mathrm{Mg}$ phase were detected in all samples, indicating that a small amount of non-reacted $\mathrm{Mg}$ still remained. The diffraction peaks belonging to the BCC-type structure are clearly seen at $\sim 42^{\circ}$ in the samples with concentration above 
$5 \mathrm{~mol} \%$ of both type of additives. The diffraction peaks of the $\mathrm{TiCr}_{1,2} \mathrm{~V}_{0,8}$ additive are slightly broader than $\mathrm{TiCrV}$. The presence of $\mathrm{Mg}$ oxide and hydride phases containing additives species were not observed in the XRD patterns of the powders mixtures after processing.

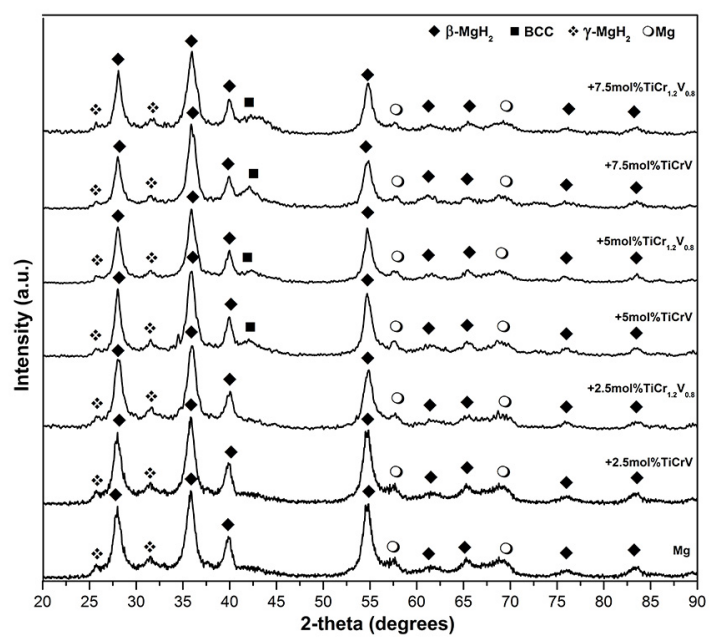

Figure 2. XRD patterns of $\mathrm{Mg}$ pure and $\mathrm{Mg}$-based nanocomposites containing 2.5, 5 and $7.5 \mathrm{~mol} \%$ of $\mathrm{TiCrV}$ and $\mathrm{TiCr}_{1.2} \mathrm{~V}_{0.8}$ milled under hydrogen for 24 hours.

Other interesting features can be seen in the XRD patterns of Figure 2. The profile of the Bragg peaks of the majority $\beta-\mathrm{MgH}_{2}$ phase is typical of ball milled samples where both reduction of the grain size and the presence of micro-strains lead to peak broadening and a decreased diffraction intensity. The average crystallite size of $\beta-\mathrm{MgH}_{2}$ phase was estimated by Scherrer analysis in all samples and it provided an estimation of the average crystallite size of around $10 \mathrm{~nm}$ in all samples without any significant difference regarding to the additive type and the amount used. Apparently, this result shows that there is no influence of additive type on crystallite size reduction of $\beta-\mathrm{MgH}_{2}$, with the milling conditions used here. Nanograin sizes of $\beta-\mathrm{MgH}_{2}$ phase, in the same range were observed in the reference ${ }^{21}$ when the $\mathrm{Mg}$ was ball milled under hydrogen atmosphere.

Figure 3a shows the DSC curves for $\mathrm{Mg}$ pure and Mg-based nanocomposites containing 2.5, 5.0 and $7.5 \mathrm{~mol} \%$ of TiCrV and 2.5, $5.0 \mathrm{~mol} \%$ of $\mathrm{TiCr}_{1.2} \mathrm{~V}_{0.8}$. The onset and the peak temperatures are indicated in the top of each curve. The DSC curves for all nanocomposites show a significant decrease in the desorption temperature ranges compared with the Mg pure, showing an important catalytic effect of the additives. Furthermore, all samples showed the presence of only endothermic peaks with the nanocomposites having desorption temperature range much broader than the pure sample. The QMS analysis indicated only hydrogen release associated to all DSC peaks and for all samples. This feature can be well illustrated by looking into Figure $3 \mathrm{~b}$ for the
Mg-pure sample where the QMS analysis has only indicated the hydrogen release.
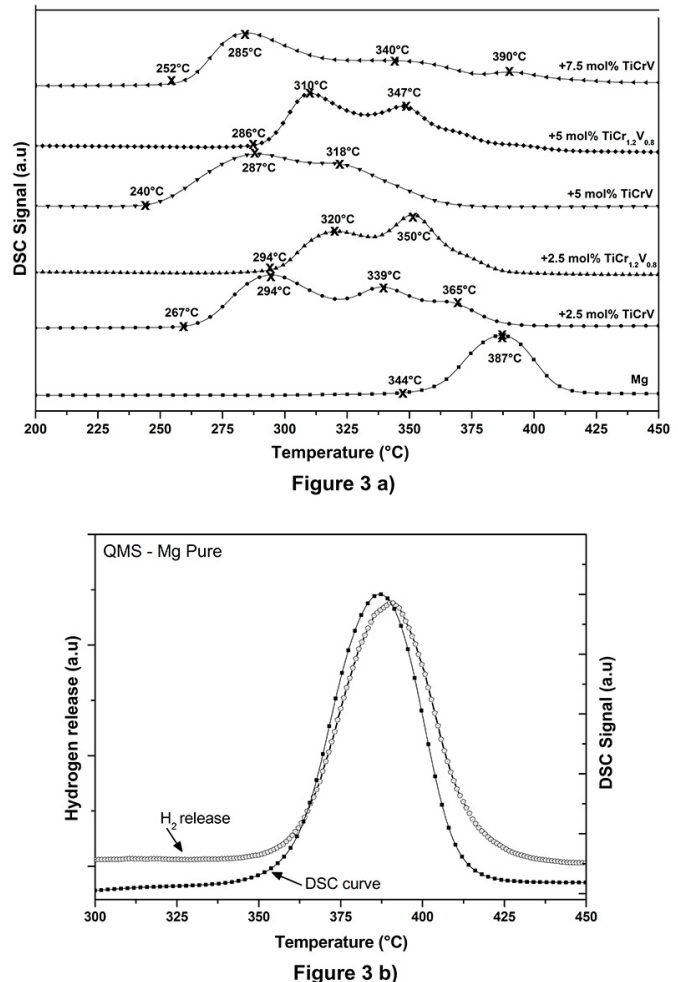

Figure 3. (a) DSC curves for $\mathrm{Mg}$ pure and for $\mathrm{Mg}$ containing 2.5, 5 and $7.5 \mathrm{~mol} \%$ of TiCrV and 2.5 and $5 \mathrm{~mol} \%$ of $\mathrm{TiCr}_{12} \mathrm{~V}_{0.8}$ after $\mathrm{RM}$. The values for the onset and peak temperatures are included in the top of each curve. (b) QMS analysis for Mg pure sample after reactive milling indicating only the hydrogen release from the DSC peak.

As we can clearly see, the addition of $\mathrm{TiCrV}$ or $\mathrm{TiCr}_{1.2} \mathrm{~V}_{0.8}$ dramatically changes the desorption temperature range independently of the concentration added into the $\mathrm{Mg}$. For the samples containing $\operatorname{TiCr}_{1.2} \mathrm{~V}_{0.8}$, the DSC curves present two very well endothermic peaks while for the samples containing TiCrV three endothermic peaks are observed (while for the $\mathrm{Mg}$ pure sample only one single peak is observed). The occurrence of double or tree peaks of desorption should be related to: (a) to the heterogeneous distribution of the particle size after milling (feature not observed during the further SEM analysis, Figure 4) $)^{21}$; (b) the coexistence of $\gamma$ and $\beta-\mathrm{MgH}_{2}$ phases and their different dissolution steps in hydrogen desorption ${ }^{22}$ (as already observed in XRD analysis, but less likely to play a role here since that the pure $\mathrm{Mg}$ sample has indicated the presence of both hydride phases and only one single peak was observed); (c) more probably due to the decomposition of hydride phases formed with the additives species, likely $\mathrm{TiH}_{2}$ or $\mathrm{TiCrVH}_{5,7}$ (FCC phase). These phases are very hard to noticed in the XRD patterns shown in Figure 2 mainly because of the proximity in $2 \Theta$ with the 
majority $\mathrm{MgH}_{2}$ phase. But some previous studies ${ }^{23,24}$ already reported the incidence of at least two or three desorption peaks of Ti-Cr-V alloy in the hydrogenated state regarding to the decomposition of the hydride $\mathrm{TiH}_{2}$ or $\mathrm{TiCrVH}_{5,7}$ phases. These hydrides, $\mathrm{TiH}_{2}$ and $\mathrm{TiCrVH}_{5,7}$, are very stable since the desorption occurs at temperatures higher than $557^{\circ} \mathrm{C}$ in the as-received state due to the stronger bond $\mathrm{Ti}-\mathrm{H}^{20}$. But when TiCrV alloys are prepared by RM, lower desorption temperatures are observed ${ }^{25}$.

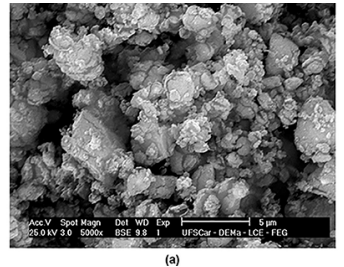

Figure 4. SEM micrographs (BSE images) for the nanocomposites: (a) $\mathrm{MgH}_{2}+5 \mathrm{~mol}_{0} \mathrm{TiCrV}$ and (b) $\mathrm{MgH}_{2}+5 \mathrm{~mol} \% \mathrm{TiCr}_{1.2} \mathrm{~V}_{0.8}$.

Based on the values presented at Figure 3 for the onset temperatures, both additives used were effective in the reduction of desorption temperature ranges. However, TiCrV was more effective than $\mathrm{TiCr}_{1,2} \mathrm{~V}_{0.8}$ for reducing the desorption temperature of $\mathrm{MgH}_{2}$ (reducing the onset temperature from $344^{\circ} \mathrm{C}$ to $240{ }^{\circ} \mathrm{C}$ in the best sample). The best results are observed in the following sequence: $\mathrm{Mg}$ containing $5 \mathrm{~mol} \%$ of TiCrV followed by 7,5 mol\% of TiCrV; $2,5 \mathrm{~mol} \%$ of TiCrV; 5 mol\% of $\operatorname{TiCr}_{1.2} \mathrm{~V}_{0.8}$ and $2,5 \mathrm{~mol} \%$ of $\mathrm{TiCr}_{1,2} \mathrm{~V}_{0,8}$. From the Figure 3 analysis, we can concluded that $5 \%$ mol. is an optimum concentration value for doping of $\mathrm{Mg}$ and the further increase of $\mathrm{TiCrV}$ content to $7,5 \mathrm{~mol} \%$ elevates the onset temperature being almost similar to the amount of $2,5 \mathrm{~mol} \%$.

SEM images obtained in back-scattered electrons (BSE) mode for the nanocomposites containing $5 \mathrm{~mol} \%$ of $\mathrm{TiCrV}$ and $\mathrm{TiCr}_{1.2} \mathrm{~V}_{0.8}$ are shown in Figure 4. These images reveal a morphology type characterized by very fine agglomerates containing particles with different formats (with planar and spherical faces) and average size around 0,3 - $5 \mu \mathrm{m}$. Again, there is no notable differences according to the additive type used, confirming that the milling time employed (24 $\mathrm{h}$ ), was not only enough to reduce $\mathrm{Mg}$ and additive to the same particle size scale but also to result in a good level of mixing and homogeneity between them.

The nanocomposite containing $5 \mathrm{~mol} \%$ of $\mathrm{TiCrV}$ was selected for a detailed TEM investigation. Figure 5 shows (a) bright field (BF) and (b) dark field (DF) STEM images showing the selected area for X-ray mapping. These images shows the presence of small agglomerates (black and gray in BF image) with grain sizes around $12-20 \mathrm{~nm}$. The nanosize of the particles is in agreement with values estimated by the Scherrer analysis. The elemental X-ray mapping (100x100 $\mathrm{nm}^{2}$ scanning area) of elements $\mathrm{Ti}, \mathrm{Cr}$ and $\mathrm{V}$ are shown in
Figure 6(a) to 6(c).The mapping reveals that the agglomerate region is partially composed by additive particles $\mathrm{Ti}, \mathrm{Cr}$ and $\mathrm{V}$ which appears brighter in their respective maps, beyond $\mathrm{Mg}$ (not mapped, but can be understood as the dark regions in each map). Also, the additives particles appear relatively in low amount and are very well distributed over the $\mathrm{Mg}$ matrix. The additive particles have grains in the same range of the Mg particles. This good level of homogeneity seen in the mixture is in agreement with the SEM images. A more refined analysis from the maps show that they look similar. However, for some areas, the Ti seems to be in high concentration in comparison to the others, indicating that the additive could probably decompose during milling. This was already reported by $\operatorname{Santos}^{25}$ during the reactive milling of BCC alloys.
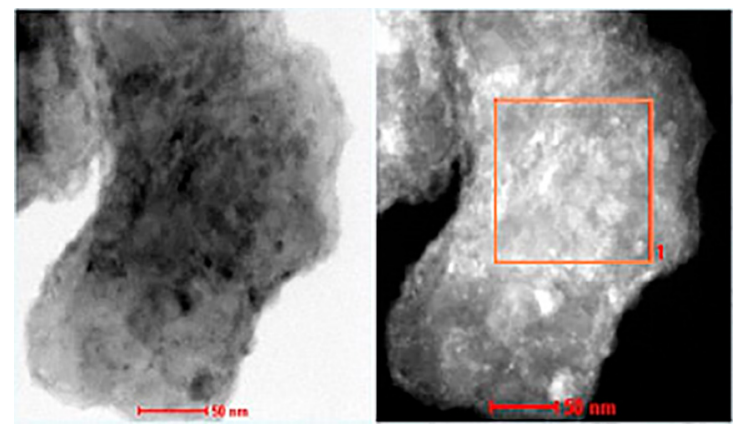

Figure 5. TEM images of the nanocomposite containing $\mathrm{Mg}+5$ mol\% TiCrV. In the left the bright field (BF) image and in the right the dark field (DF) image, highlighting the scanned area.

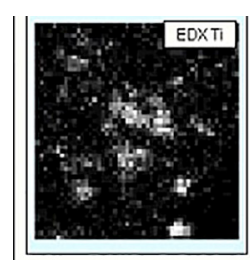

a)

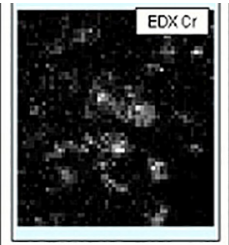

b)

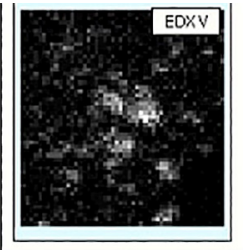

c)
Figure 6. X-ray mapping of the additive elements: (a) Ti; (b) $\mathrm{Cr}$; (c) $\mathrm{V}$ for the nanocomposite containing $5 \mathrm{~mol} \% \mathrm{TiCrV}$. Scanning area of $100 \times 100 \mathrm{~nm} 2$.

Finally, the desorption and absorption kinetics at $275^{\circ} \mathrm{C}$ and $300{ }^{\circ} \mathrm{C}$ for the $\mathrm{Mg}$ pure and the nanocomposites containing $5 \mathrm{~mol} \%$ of TiCrV and $\mathrm{TiCr}_{1,2} \mathrm{~V}_{0,8}$ are shown in Figure 7 (a) and Figure (7b). For the desorption at $275^{\circ} \mathrm{C}$ under 1 bar of hydrogen pressure, the pure $\mathrm{Mg}$ sample did not release any hydrogen and its curve was not recorded while for the nanocomposites containing $\mathrm{TiCrV}$ and $\mathrm{TiCr}_{1.2} \mathrm{~V}_{0.8}$ a partial hydrogen desorption was observed, releasing $5.4 \mathrm{wt} . \%$ of hydrogen in 15 minutes. For the subsequent absorption at $275^{\circ} \mathrm{C}$ under 20 bar of hydrogen pressure, the nanocomposites 
presented again the same kinetic behavior, absorbing the same amount of hydrogen in approximately 8 minutes.
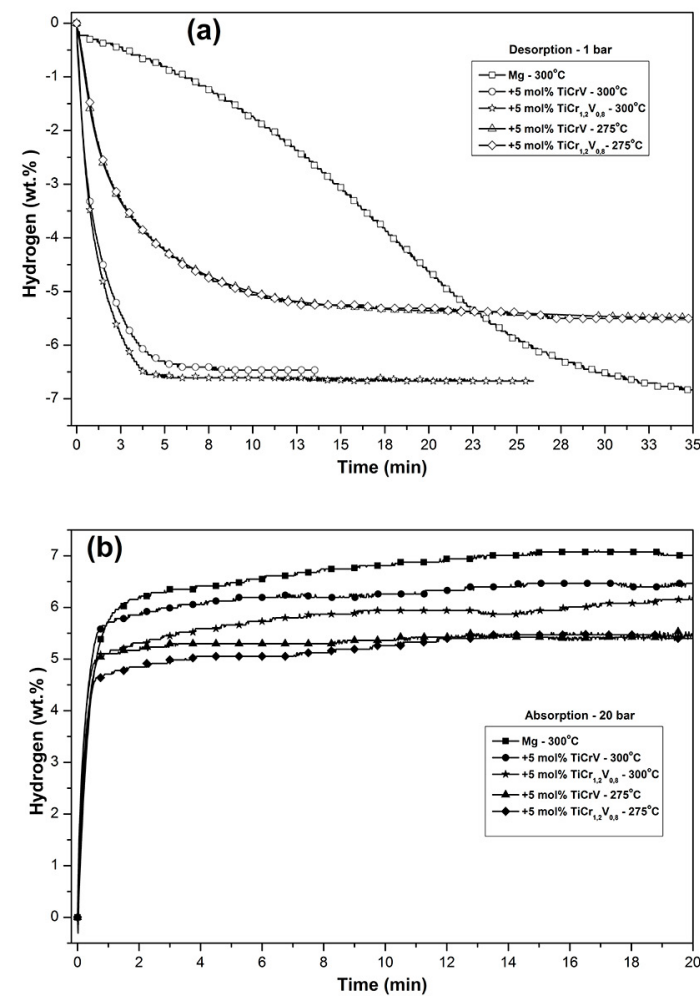

Figure 7. (a) Desorption kinetics at $275^{\circ} \mathrm{C}$ and $300^{\circ} \mathrm{C}$ for the pure $\mathrm{Mg}$ and for the nanocomposites containing $5 \mathrm{~mol} \%$ of $\mathrm{TiCrV}$ and $\mathrm{TiCr}_{1,2} \mathrm{~V}_{0,8}$ under 1 bar of hydrogen pressure. (b) Absorption kinetics at $275^{\circ} \mathrm{C}$ and $300^{\circ} \mathrm{C}$ for the pure $\mathrm{Mg}$ and for the nanocomposites containing $5 \mathrm{~mol} \%$ of $\mathrm{TiCrV}$ and $\mathrm{TiCr}_{1,2} \mathrm{~V}_{0,8}$ under 20 bar of hydrogen pressure.

When the temperature is increased up to $300^{\circ} \mathrm{C}$, the kinetic behavior and the hydrogen capacity between the samples are changed. The desorption and absorption kinetics becomes faster and the hydrogen capacity measured is slight higher than at 275 ${ }^{\circ} \mathrm{C}$. At $300{ }^{\circ} \mathrm{C}$, the nanocomposite containing $\mathrm{TiCrV}$ released 6.5 wt. $\%$ against 6.7 wt. $\%$ of the one containing $\operatorname{TiCr}_{1.2} \mathrm{~V}_{0.8}$. Nevertheless, both additives presented very fast desorption kinetic behavior, releasing those amounts of hydrogen after 7 minutes. For the subsequent absorption, their hydrogen capacities are reached, again, after 8 minutes. It interesting to point out that for the both additives tested here, different desorption behavior based on DSC analysis were presented but very similar kinetic properties were observed. It worth to point out that the DSC measurements were performed in the powders samples immediately after milling.

Not less important, the $\mathrm{Mg}$ pure sample needed more than 50 minutes to complete its desorption at $300^{\circ} \mathrm{C}$, but it showed, as expected, a higher hydrogen capacity, releasing about 7.3 wt. $\%$ of hydrogen. For the absorption at $300^{\circ} \mathrm{C}$, the $\mathrm{Mg}$ pure sample presented a very fast hydrogen storage capacity.

We have observed that when the kinetics measurements are only carried out at a condition where the driving force was too high, i.e. 275 and $350^{\circ} \mathrm{C} \mathrm{K}$ under 20 bar of $\mathrm{H}_{2}$, the effects between the both additives tested could be hardly noticed. For the samples containing additives, the absorption process is found to mainly depend on temperature and pressure conditions and, in this case, the role of the microstructure which appears very refined and homogeneous as indicated by SEM and TEM analysis, seems to play a more important role. While for the desorption kinetics, it starts first in the mixtures instead of the pure sample. It due to fact that the additive particles act as catalysts, dissociating $\mathrm{H}_{2}$ molecules into $\mathrm{H}$ atoms, which could diffuse more easily along the grain boundaries between magnesium and the additive materials $\mathrm{s}^{7,26}$.

\section{Conclusions}

The following conclusions could be drawn from this investigation:

- After milling, the powders samples showed the presence of the hydride phases, $\beta$ and $\gamma-\mathrm{MgH}_{2}$ (high-pressure phase) and the BCC alloy structure (for samples with concentration of $\mathrm{TiCrV}$ and $\mathrm{TiCr}_{1,2} \mathrm{~V}_{0,8}$ higher than $5 \mathrm{~mol} \%$.). Nanograin sizes around of $\sim 10 \mathrm{~nm}$ and good level of homogeneity were also observed as typically noticed in ball milled powders.

- The doping with $\mathrm{TiCrV}$ and $\mathrm{TiCr}_{1,2} \mathrm{~V}_{0,8}$ greatly improves the hydrogen desorption behavior of $\mathrm{Mg}$ in comparison with the sample without additive. The amount of $5 \mathrm{~mol} \%$ of $\mathrm{TiCrV}$ was slightly more effective than $\mathrm{TiCr}_{1.2} \mathrm{~V}_{0.8}$ in desorption temperature reduction $\left(\sim 240{ }^{\circ} \mathrm{C}\right)$, also this concentration showed to be an optimum value for doping $\mathrm{Mg}$ since that an increase to $7,5 \mathrm{~mol} \%$ resulted in higher desorption temperature.

- Very fast absorption and desorption kinetics at $275^{\circ} \mathrm{C}$ and $300{ }^{\circ} \mathrm{C}$ were observed for the mixtures in comparison with the $\mathrm{Mg}$ pure. At $275^{\circ} \mathrm{C}$, the pure $\mathrm{Mg}$ sample did not release any hydrogen while for the nanocomposites containing $\mathrm{TiCrV}$ and $\mathrm{TiCr}_{1,2} \mathrm{~V}_{0,8}$, a very fast hydrogen desorption was observed, releasing 5,4 wt.\% of hydrogen in 15 minutes. At $300^{\circ} \mathrm{C}$ much faster hydrogen desorption ( $\sim 7 \mathrm{~min}$.) and higher hydrogen capacity (6.7 wt.\%) were observed. The improvements in kinetics could be associated to: (a) the refined microstructure; (b) the good level of mixing and; (c) the catalytic effect of additives during absorption and desorption processes.

\section{Acknowledgments}

The authors wish to thank CAPES and CNPq for the financial support. 


\section{References}

1. Niaz S, Manzoor T, Pandith AH. Hydrogen storage: Materials, methods and perspectives. Renewable and Sustainable Energy Reviews. 2015;50:457-469.

2. Wang H, Lin HJ, Cai WT, Ouyang LZ, Zhu M. Tuning kinetics and thermodynamics of hydrogen storage in light metal element based systems - A review of recent progress. Journal of Alloys and Compounds. 2016;658:280-300.

3. De Castro JFR, Santos SF, Costa ALM, Yavari AR, Botta WJ, Ishikawa TT. Structural characterization and dehydrogenation behavior of $\mathrm{Mg}-5$ at. $\% \mathrm{Nb}$ nano-composite processed by reactive milling. Journal of Alloys and Compounds. 2004;376(1-2):251-256.

4. Floriano R, Leiva DR, Deledda S, Hauback BC, Botta WJ. $\mathrm{MgH}_{2}-$ based nanocomposites prepared by short-time high energy ball milling followed by cold rolling: A new processing route. International Journal of Hydrogen Energy. 2014;39(9):4404-4413.

5. House SD, Vajo JJ, Ren C, Rockett AA, Robertson IM. Effect of ball-milling duration and dehydrogenation on the morphology, microstructure and catalyst dispersion in Ni-catalyzed $\mathrm{MgH}_{2}$ hydrogen storage materials. Acta Materialia. 2015;86:55-68.

6. Hanada N, Hirotoshi E, Ichikawa T, Akiba E, Fujii H. SEM and TEM characterization of magnesium hydride catalyzed with Ni nano-particle or $\mathrm{Nb}_{2} \mathrm{O}_{5}$. Journal of Alloys and Compounds. 2008;450(1-2):395-399.

7. Liang G, Huot J, Boily S, van Neste A, Schulz R. Catalytic effect of transition metals on hydrogen sorption in nanocrystalline ball milled $\mathrm{MgH}_{2}-\mathrm{Tm}(\mathrm{Tm}=\mathrm{Ti}, \mathrm{V}, \mathrm{Mn}, \mathrm{Fe}$ and $\mathrm{Ni})$ systems. Journal of Alloys and Compounds. 1999;292(1-2):247-259.

8. Yavari AR, LeMoulec A, de Castro FR, Deledda S, Friedrichs O, Botta WJ, et al. Improvement in H-sorption kinetics of $\mathrm{MgH}_{2}$ powders by using $\mathrm{Fe}$ nanoparticles generated by reactive $\mathrm{FeF}_{3}$ addition. Scripta Materialia. 2005;52(8):719-724.

9. Chen D, Wang YM, Chen L, Liu S, Ma CX, Wang LB. Alloying effects of transition metals on chemical bonding in magnesium hydride $\mathrm{MgH}_{2}$. Acta Materialia. 2004;52(2):521-528.

10. Shang CX, Bououdina M, Song Y, Guo ZX. Mechanical alloying and electronic simulations of $\left(\mathrm{MgH}_{2}+\mathrm{M}\right)$ systems $(\mathrm{M}=\mathrm{Al}, \mathrm{Ti}$, $\mathrm{Fe}, \mathrm{Ni}, \mathrm{Cu}$ and $\mathrm{Nb}$ ) for hydrogen storage. International Journal of Hydrogen Energy. 2004;29(1):73-80.

11. Nomura K, Akiba E. $\mathrm{H}_{2}$ Absorbing-desorbing characterization of the Ti-V-Fe alloy system. Journal of Alloys and Compounds. 1995;231(1-2):513-517.

12. Iba H, Akiba E. The relation between microstructure and hydrogen absorbing property in Laves phase-solid solution multiphase alloys. Journal of Alloys and Compounds. 1995;231(1-2):508-512.

13. Akiba E, Iba H. Hydrogen absorption by Laves phase related BCC solid solution. Intermetallics. 1998;6(6):461-470.
14. Itoh H, Arashima H, Kubo K, Kabutomori T. The influence of microstructure on hydrogen absorption properties of $\mathrm{Ti}-\mathrm{Cr}-\mathrm{V}$ alloys. Journal of Alloys and Compounds. 2002;330-332:287-291.

15. Sorescu M, Gabrias A, Valeanu M. Symmetry and hyperfine magnetic fields in Nd-based intermetallics. Intermetallics. 2001;9(1):67-71.

16. Yan Y, Chen Y, Liang H, Wu C, Tao M, Mingjing T. Effect of $\mathrm{Al}$ on hydrogen storage properties of $\mathrm{V}_{30} \mathrm{Ti}_{35} \mathrm{Cr}_{25} \mathrm{Fe}_{10}$ alloy. Journal of Alloys and Compounds. 2006;426(1-2):253-255.

17. Chen L, Li L, Wang X, Dai F, Zheng F, Lei Y. Phase structures and electrochemical properties of $\mathrm{V}_{2.1} \mathrm{TiNi}_{0.4} \mathrm{Zr}_{\mathrm{x}}(x=0-0.06)$ hydrogen storage electrode alloys. Acta Physico-Chimica Sinica. 2006;22(5):523-527

18. Martínez A, dos Santos DS. Hydrogen absorption/desorption properties in the TiCrV based alloys. Materials Research. 2012;15(5):809-812.

19. Asano K, Enoki H, Akiba E. Synthesis process of Mg-Ti $\mathrm{BCC}$ alloys by means of ball milling. Journal of Alloys and Compounds. 2009;486(1-2):115-123.

20. Lin HC, Lin KM, Wu KC, Hsiung HH, Tsai HK. Cyclic hydrogen absorption-desorption characteristics of TiCrV and $\mathrm{Ti}_{0.8} \mathrm{Cr}_{1.2} \mathrm{~V}$ alloys. International Journal of Hydrogen Energy. 2007;32(18):4966-4972.

21. Varin RA, Czujko T, Chiu Ch, Wronski ZJ. Particle size effects on the desorption properties of nanostructured magnesium dihydride $\left(\mathrm{MgH}_{2}\right)$ synthesized by controlled reactive mechanical milling (CRMM). Journal of Alloys and Compounds. 2006;424(1-2):356-364.

22. Gennari FC, Castro FJ, Urretavizcaya G. Hydrogen desorption behavior from magnesium hydrides synthesized by reactive mechanical alloying. Journal of Alloys and Compounds. 2001;321(1):46-53.

23. Shashikala K, Banerjee S, Kumar A, Pai MR, Pillai CGS Improvement of hydrogen storage properties of TiCrV alloy by $\mathrm{Zr}$ substitution for Ti. International Journal of Hydrogen Energy. 2009;34(16):6684-6689.

24. Liu X, Huang Z, Jiang L, Wang S. Thermal stabilization and hydrogen storage properties of $\mathrm{Mg}-40 \mathrm{wt} \% \mathrm{Ti}_{0.28} \mathrm{Cr}_{0.50} \mathrm{~V}_{0.22}$ composite prepared by mechanical milling. International Journal of Hydrogen Energy. 2007;32(8):965-968.

25. Santos SF, Costa ALM, de Castro JFR, dos Santos DS, Botta WJ, Ishikawa TT. Mechanical and reactive milling of a TiCrV BCC solid solution. Journal of Metastable and Nanocrystalline Materials. 2004;20-21:291-296.

26. Rivoirard S, de Rango P, Fruchart D, Charbonnier J, Vempaire D. Catalytic effect of additives on the hydrogen absorption properties of nano-crystalline $\mathrm{MgH}_{2}(\mathrm{X})$ - composites. Journal of Alloys and Compounds. 2003;356-357:622-625. 